\title{
Podcast como recurso de aprendizagem: um elo entre as mídias digitais, a aprendizagem significativa e o educar pela pesquisa
}

\author{
Márcia Jussara Hepp Rehfeldt ${ }^{1}$ \\ Maurício Severo da Silva ${ }^{2}$
}

\begin{abstract}
RESUMO
Trata-se de uma pesquisa qualitativa em que o pesquisador buscou, por meio de sua proposta pedagógica, fazer uma interface entre a criação de episódios de podcast de autoria discente e conceito de educar pela pesquisa de Demo (2011a) embasado na teoria de aprendizagem significativa de Ausubel (2003). Utiliza essa teoria de Ausubel para tentar responder a seguinte questão-problema: Quais são as implicações da utilização da mídia podcast, enquanto recurso de aprendizagem autônoma e potencialmente significativa, por estudantes do ensino superior na disciplina Tópicos Especiais em Computação? A análise dos dados, realizada com o auxílio do software NVIVO, teve como principais resultados: a prática pedagógica proposta, que se qualifica como sendo uma nova opção dentre as metodologias ativas disponíveis; a proposta de um modelo reflexivo que contribui para a elaboração de outras práticas pedagógicas que utilizem mídias digitais com base nos pressupostos teóricos da aprendizagem significativa e do educar pela pesquisa.
\end{abstract}

PALAVRAS-CHAVE: Mídias digitais; Aprendizagem Significativa; Educar pela Pesquisa; Recurso de aprendizagem; Podcast;

Podcast as learning resource: a link between digital media, significant learning and Education through Investigation

\footnotetext{
ABSTRACT

${ }^{1}$ Doutora em Informática na Educação. Universidade do Vale do Taquari - Univates, Lajeado, Rio Grande do Sul, Brasil. https://orcid.org/0000-0002-0007-8639.mrehfeld@univates.br.

2 Mestre em Ensino. Universidade do Vale do Taquari - Univates, Lajeado, Rio Grande do Sul, Brasil. https://orcid.org/0000-0003-1271-6981.mss@univates.br.
} 
It is a qualitative research with methodologic approach related to a case study in which the researcher investigated, by means of his pedagogic proposal, to develop an interface between the creation of student's podcast episodes and the concept of Education through Investigation from Demo (2011a) based on Ausubel's (2003) theory of significant learning. We used this Ausubel's theory in order to try answering the following problem-question: Which are the implications of using the podcast media as an autonomous and potentially significant learning resource with college students in the subject of Special Topics on Computing? The data analysis was held with the help of NVIVO software as had as main results the pedagogic proposal, which qualifies itself as being a new option among the available active methodologies; the proposal of a reflexive model that contributes to the development of other pedagogic practices that use digital.

KEYWORDS: Digital Media; Significant Learning; Educating through Investigation; Learning Resource; Podcast.

\section{Introdução}

$\mathrm{Na}$ tentativa de tornar as atividades de sala de aula mais atrativas e, ao mesmo tempo, instigar os estudantes a serem autores e autônomos em seu processo de aprendizado, os pesquisadores elaboraram uma atividade em que utilizaram os preceitos da Aprendizagem Significativa de Ausubel (2003), em consonância com o que propõe Demo (2011a) ao definir o educar pela pesquisa.

A aproximação proposta neste trabalho entre a aprendizagem significativa de Ausubel (2003) e a proposta de educar pela pesquisa de Demo (2011a) justifica-se pela necessidade de melhorar o processo formativo pelo qual os estudantes da área da computação vivenicam. Com base no que afirma Demo (2011a), ao discorrer sobre o processo formativo dentro das universidades, percebe-se que "é comum aceitar-se a ideia de que, ao sair da universidade e assumir um emprego, será mister aprender tudo de novo", 
pois existem lacunas formativas associadas às habilidades e competências necessárias para os diferentes profissionais, incluindo os área da Computação, no que concerne à: "saber pensar, aprender a aprender e intervir de modo inovador e ético" (DEMO, 2011a, p.72).

Essa situação se agrava quando os egressos da área da Tecnologia da Informação (TI) conversam com outros profissionais em formação. É comum o sentimento de que apenas a graduação não basta, que são necessários cursos, especializações e que, por mais que estudem, sempre estarão em busca das inovações tecnológicas que permeiam a área. Posto isso, é certo afirmar que, tão importante quanto construir ementas e/ou elaborar materiais que abordem tópicos atualizados, é a necessidade de formar sujeitos que se promovam da sua aprendizagem e que sejam capazes de aprender de forma autônoma (DEMO, 2011a) e significativa (AUSUBEL, 2003).

Isso justifica o motivo pelo qual, mesmo possuindo trabalhos como os de Saeed (2010), Moura e Carvalho (2006) e Carvalho et al. (2008) que comprovam que a mídia podcast tem potenciais a serem explorados enquanto objeto de aprendizagem, neste trabalho, os pesquisadores optaram por apresentar uma proposta de utilização do podcast como estratégia de aprendizagem. Isso se justifica uma vez que apenas expor os estudantes ao conteúdo gerado por terceiros não modifica a realidade passiva de formação, que considera o estudante um sujeito capaz apenas de reproduzir o que lê, vê e escuta.

Dessa forma, o estudo se propôs a trabalhar com o viés educativo indicado por Demo (2011a) mediante a construção de episódios de podcast, cujo conteúdo fosse resultante de pesquisas científicas realizadas pelos discentes. Além disso, compreendemos a utilização do podcast enquanto estratégia de aprendizagem potencialmente significativa propicia ao estudante a oportunidade de investigar temas de sua preferência e estimulao a ser protagonista de sua aprendizagem. 
O estudo teve como objetivo geral investigar as implicações da utilização da mídia podcast como estratégia para instigar a autonomia e a autoria discente na aprendizagem dos estudantes da disciplina Tópicos Especiais em Computação, inserida nos cursos de Sistemas de Informação, Engenharia da Computação, Engenharia de Software e Redes de Computadores da Universidade do Vale do Taquari - Univates.

O presente texto focalizará a proposta pedagógica elaborada pelos pesquisadores e o modelo reflexivo, para uso das mídias digitais com base nos pressupostos teóricos da aprendizagem significativa e do educar pela pesquisa. Dessa forma, os resultados relativos à investigação acerca da aprendizagem dos estudantes bem como da autonomia e autoria instigada pelo docente serão abordados de forma mais tangencial, devido ao espaço de que dispomos nesse relato de pesquisa.

\section{Mídias digitais no ensino, Aprendizagem Significativa e o educar pela pesquisa}

Existem diversos estudos que propõem o uso das mídias digitais no ensino. É possível citar os trabalhos de Domingues (2014), Leão, Rehfeldt e Marchi (2015), que desnudam as potencialidades dos vídeos em contextos educacionais; Lévy e Costa (1997) que, ainda no milênio passado, apresentam em seu trabalho o impacto do hipertexto na forma como as pessoas se comunicam e como essa tecnologia poderia ser melhor aproveitada em contextos de ensino. Relacionado à mídia podcast, pode-se destacar o trabalho de Eugênio Freire (2013), no qual o pesquisador realizou uma revisão da literatura sobre o uso educacional do podcast e como este recurso pode ser utilizado para dar voz aos estudantes.

Para além dos estudos, poder-se-iam utilizar iniciativas como o KhanAcademy e YouTube Edu para destacar a importância dos vídeos e outras mídias digitais no ensino. Ainda assim, o uso das mídias digitais, tanto para o ensino quanto para a aprendizagem, requer que o docente 
possua propósitos educacionais bem definidos e claros, conforme propõe Demo (2016b).

O ponto central de reflexão do docente quanto ao uso das mídias digitais no ensino deve ser o fato de que não basta substituir aulas presenciais expositivas por vídeos, ou, utilizar as mídias digitais como meros artifícios para deixar as aulas divertidas (DEMO, 2016b). Em consonância com essa afirmativa, Demo (2016b) argumenta que a simples produção de aulas em vídeo continua por apenas expor os estudantes de forma passiva ao conteúdo e que, dessa maneira, o professor mantém a errônea ideia de "causador" da aprendizagem. Para Demo (2016b), os docentes deveriam privilegiar a autoria discente estimulando os estudantes a produzirem seus próprios vídeos. Segundo o autor, “o que interessaria aí, mais que tudo, é como o estudante faz o vídeo, tornando-se autor do conteúdo, não seu consumidor ou papagaio" (DEMO, 2016b, s/p).

A visão de Demo (2016b) quanto ao uso dos vídeos evidencia o desafio que é a utilização das mídias digitais como recurso didático-pedagógico nos diversos níveis de ensino, incluindo, o ensino superior, em que o uso dessas tecnologias digitais tem aumentado, conforme aponta Lames (2011). Essa última autora revela que um dos desafios está relacionado com a forma com que as mídias digitais são inseridas na metodologia de ensino utilizada pelos professores. A autora destaca que os docentes não podem incidir no erro de transpor as metodologias tradicionais de ensino para os meios digitais. Seguindo a perspectiva de Demo (2016b), se não houver a reflexão crítica, as mídias digitais serão utilizadas apenas para subtrair parte do viés instrucionista que não modifica a realidade passiva do estudante. Além disso, ao agir dessa forma, o docente ignora os conhecimentos prévios do estudante durante a escolha do tipo de mídia e, também, do seu conteúdo, o que segundo Ausubel (2003), diminui substancialmente a possibilidade de que uma aprendizagem significativa ocorra.

Lames (2011) concorda com diversos outros autores (DEMO; 2004, 2011a, 2016b, 2016c, 2018; PRENSKY, 2001) quando afirma que é sempre 
necessária a reflexão do professor sobre seu papel em sala de aula. Lames (2011) defende que,

para superar o uso inadequado das tecnologias na educação é fundamental que o professor saiba o que é aprender e o que é ensinar, como os alunos aprendem e propor, assim, metodologias ativas e novas de produzir, comunicar e representar o conhecimento, possibilitadas pelas novas mídias [...] (LAMES, 2011, p. 23).

A reflexão sobre o que propõe a autora faz com que seja possível apresentar o que pode ser um novo elo que liga, de forma coerente as mídias digitais, a teoria de aprendizagem significativa de Ausubel (2003) e a proposta educacional de educar pela pesquisa de Demo (2011a).

Para tornar isso evidente, é preciso compreender a posição de Lames (2011). A autora destaca que "para superar o uso inadequado das tecnologias na educação é fundamental que o professor saiba” (LAMES, 2011, p. 23): o que é aprender; o que é ensinar; como os alunos aprendem; propor [..] metodologias ativas e noas de produzir, comunicar e representar o conhecimento, possibilitadas pelas novas mídias. Neste trabalho, cada um desses itens será trabalhado de forma independente nas próximas seções de modo a evidenciar o referido elo entre mídias digitais, a teoria de aprendizagem significativa e o educar pela pesquisa.

\section{O que é aprender}

Aprendizagem, na perspectiva de Ausubel (2003), é um processo no qual o indivíduo armazena informações em sua estrutura cognitiva por meio da subsunção das novas ideias já existentes. Para Demo (2004, 2009, 2011a, 2011b), a aprendizagem é um processo autopoiético, que ocorre de dentro 
para fora de forma reconstrutiva, conforme proposto por Maturana e Varela (1994).

Percebe-se que o processo de subsunção de ideias proposto por Ausubel (2003) não é dicotômico com a ideia de aprendizagem por processo autopoiético. Ambos os processos procuram explicar, a seu modo, o movimento da aprendizagem. Um, em uma perspectiva teórica com base na psicologia, e outro, em uma perspectiva biológica. Em termos teóricos, a aprendizagem por meio da subsunção apresentada por Ausubel (2003) muito se assemelha à de autopoiese, proposta por Maturana e Varela (1994).

\section{O que é ensinar}

Para Ausubel (2003), ensinar é um processo próximo ao de pesquisar. Segundo o autor, o docente precisa investigar os conhecimentos prévios dos estudantes para ter subsídios para elaborar seu material didático de modo a torná-lo potencialmente significativo. Diante disso, o autor defende que o docente deve conhecer como funciona o processo de aquisição de novas palavras e conceitos e propor metodologias de ensino que facilitem estes processos.

Assim como em uma pesquisa, o docente que utiliza a aprendizagem significativa como base do seu fazer docente pode coletar dados; refletir sobre eles e adotar estratégias/métodos de como potencializar seu uso. Como resultado da "pesquisa", o docente apresenta um ambiente educacional potencialmente significativo para seus estudantes, seja por conta de um material didático próprio ou pelo uso de metodologias de ensino apuradas com os processos de aprendizagem.

Já a concepção educativa defendida por Demo (2004, 2011a, 2016a, 2016b, 2018) propõe que o estudante seja estimulado a realizar pesquisas e, a partir delas, elaborar produções autorais, o que pode ser feito de forma escrita ou pelo uso de mídias digitais, como é o caso do podcast. $\mathrm{O}$ autor sustenta a ideia de que o estudante "aprende bem com professor que 
aprende bem" (DEMO, 2016c, texto digital). Para isso, o autor argumenta que é necessário que o docente elabore material didático próprio, que tenha como base a pesquisa e reflexão.

É possível inferir que, neste ponto, Ausubel (2003) e Demo (2011a) possuem entendimentos complementares. O primeiro desvenda como as pessoas aprendem para que seja possível planejar os materiais de estudos de modo que sejam potencialmente significativos. Já o segundo, argumenta que essa produção deve ser resultado de pesquisa própria e que tenha como resultado a autoria docente.

Em relação ao "ensinar", existe ainda um conflito na posição defendida pelos dois autores que precisa ser resolvido para que o elo entre mídias digitais, aprendizagem significativa e o educar pela pesquisa tenha consistência. Ausubel (2003) compreende o professor no centro do processo de ensino, defendendo que ele é quem precisa organizar os roteiros de estudo e atividades de ensino potencialmente significativas. Ainda assim, o autor destaca que o estudante precisa ser ativo no processo educativo para que sua aprendizagem seja significativa. Já Demo (2016c), compreende o estudante no centro do processo educativo e defende que, para aprender, ele precisa "estudar, ler, pesquisar, elaborar, não só escutar aula, fazer prova e engolir repasse" (DEMO, 2016c, texto digital).

Percebe-se que as posições teóricas dos dois autores, embora possuam perspectivas diferentes, não são autoexcludentes. Ausubel (2003) apresenta uma perspectiva teórica de como os sujeitos aprendem e desvela como os docentes podem organizar as aulas de modo que os estudantes possam ter sua aprendizagem potencializada enquanto estiverem lendo, estudando, pesquisando ou elaborando produções autorais, que é o que defende Demo (2016c).

Consideramos que ambos, professores e estudantes, possuem papéis a serem desempenhados e ambos precisam coexistir no modelo educacional vigente. A discussão que realmente importa é o fato de o professor estar em contexto para facilitar o processo de aprendizagem do estudante; o 
estudante está em contexto para aprender. Assim, compreendemos que a visão dos dois autores fornece um panorama mais completo de como os processos de ensino e de aprendizagem pode ocorrer para que o estudante aprenda de forma significativa, conforme apresentado na Figura 1.

FIGURA 1: Visões de Ausubel e Demo convergem para um mesmo local.

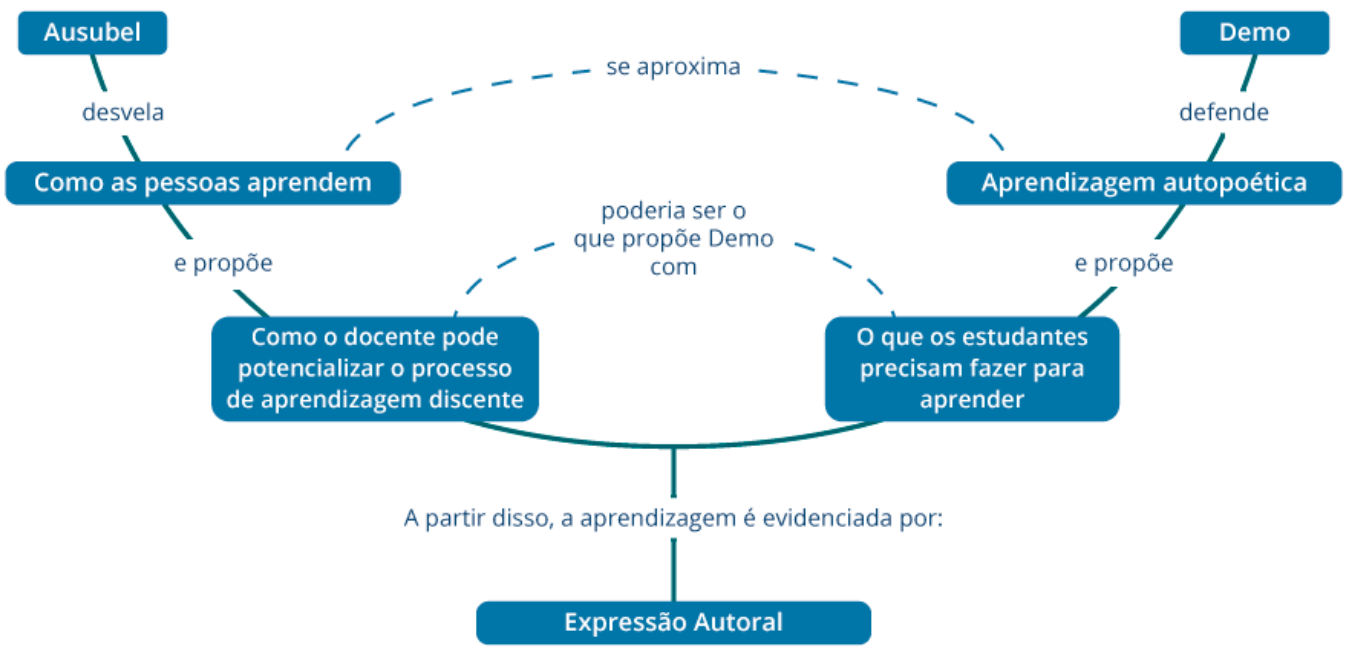

Fonte: Elaborado com base em Ausubel (2003) e Demo (2011a)

Na Figura 1 é possível visualizar a aproximação que pode ser feita entre as duas teorias. O ponto de ligação entre elas, a expressão autoral, será explicada na próxima seção.

\section{Como os alunos aprendem}

O terceiro item apontado por Lames (2011), entendido como fundamental ao professor para superar o uso inadequado das tecnologias em atividades de ensino e de aprendizagem, é compreender como a aprendizagem ocorre. Quanto a isso, Ausubel (2003) apresenta em sua teoria da aprendizagem significativa detalhes de como ela acontece nas diversas faixas etárias.

Para que seja possível evidenciar a teoria de aprendizagem significativa de Ausubel (2003), o educar pela pesquisa de Demo (2011a) e as 
mídias digitais, é preciso primeiro explicar o que é aprendizagem significativa e como ela se apresenta neste trabalho. É necessário explorar como a aprendizagem por assimilação conceitual ocorre em adultos, já que os sujeitos cuja aprendizagem foi investigada são estudantes do ensino superior.

Segundo Rehfeldt (2009), a aprendizagem por assimilação ocorre pela aquisição de novos conceitos com base na "recepção de seus atributos criteriais e pelo relacionamento desses atributos com ideias relevantes já estabelecidas na sua estrutura cognitiva" (REHFELDT, 2009, p. 34). Isso significa que é necessário, na aprendizagem por assimilação de conceitos, que existam subsunçores suficientemente estáveis e claros para que a nova ideia (ou conceito) seja ancorada.

À medida que a assimilação de novos conceitos vai ocorrendo, inicia-se o processo de assimilação obliterante. Segundo Ausubel (2003), quando a aprendizagem é significativa, ela acaba por modificar os subsunçores aos quais foi ancorada de modo que, progressivamente, seja difícil recuperar de forma exata o conceito que serviu como base para o ancoramento do novo conceito. Segundo palavras do autor, "as ideias acabadas de aprender começam a tornar-se, progressivamente, menos dissociáveis (recuperáveis) das respectivas ideias ancoradas, como entidades por direito, até deixarem de estar disponíveis e se afirmar estarem esquecidas" (AUSUBEL, 2003, p. 108). Sendo assim, a assimilação obliterante constitui-se como um recurso reducionista da estrutura geral cognitiva, que leva ao esquecimento ou à impossibilidade de dissociar o conceito previamente estabelecido do que foi modificado em virtude do ancoramento de uma nova ideia.

A aquisição de novos conceitos por meio da assimilação de conceitos, assim como na aprendizagem por proposição ${ }^{3}$, pode ocorrer de forma subordinada, superordenada ou combinatória, dependendo da forma como a nova ideia se relaciona com as já existentes. Segundo Moreira (2012), a

\footnotetext{
${ }^{3}$ Para além do conceito de aprendizagem por assimilação de conceitos, Ausubel (2003) apresenta os conceitos de aprendizagem representacional e a aprendizagem por proposição, que, pelo foco deste estudo, não cabem serem detalhados.
} 
aprendizagem subordinada ocorre "quando os novos conhecimentos potencialmente significativos adquirem significado, para o sujeito que aprende, por um processo de ancoragem cognitiva, interativa, em conhecimentos prévios relevantes mais gerais e inclusivos já existentes na sua estrutura cognitiva” (MOREIRA, 2012, p. 14). A aprendizagem superordenada, segundo Moreira (2012), envolve "processos de abstração, indução, síntese, que levam a novos conhecimentos que passam a subordinar aqueles que lhe deram origem" (MOREIRA, 2012, p. 15). Já a aprendizagem que ocorre de forma combinatória, é aquela na qual o novo conceito "implica interação com vários outros conhecimentos já existentes na estrutura cognitiva, mas não é nem mais inclusiva nem mais específica do que os conhecimentos originais" (MOREIRA, 2012, p. 16). Segundo o autor, nesse tipo de aprendizagem, os atributos criteriais possuem alguns significados comuns entre o novo conceito e os já existentes, mas não os subordina nem superordena.

Cabe destacar que tanto a aprendizagem subordinada quanto a superordenada possuem uma estrutura hierárquica entre os conceitos que, segundo Ausubel (2003), são organizados em classes e subclasses. A diferença fundamental entre a aprendizagem subordinada e superordenada é que, na primeira, o sujeito parte de um conceito mais abrangente e ancora as especializações a esse conceito mais abrangente. Já na superordenada o conceito mais genérico não está disponível na estrutura cognitiva do aprendiz, que deve, por raciocínio indutivo, generalizar os diferentes tipos de escolas para então aprender o conceito generalista de escola.

Esses dois tipos de aprendizagem descortinam outros dois processos cognitivos importantes da teoria de aprendizagem significativa, os de diferenciação progressiva e reconciliação integradora. Para Ausubel (2003), a diferenciação progressiva ocorre quando as ideias mais gerais e abrangentes são apresentadas antes e, progressivamente, são introduzidas novas ideias que permitam diferenciar a ideia generalista das mais específicas. Já no processo de reconciliação integradora ocorre o oposto, os 
conceitos mais abrangentes são apresentados primeiro. A Figura 2 ilustra uma possível estrutura hierárquica do conceito de Escola pela perspectiva da diferenciação progressiva e reconciliação integradora.

Figura 2: Processos cognitivos - diferenciação progressiva e reconciliação integradora.

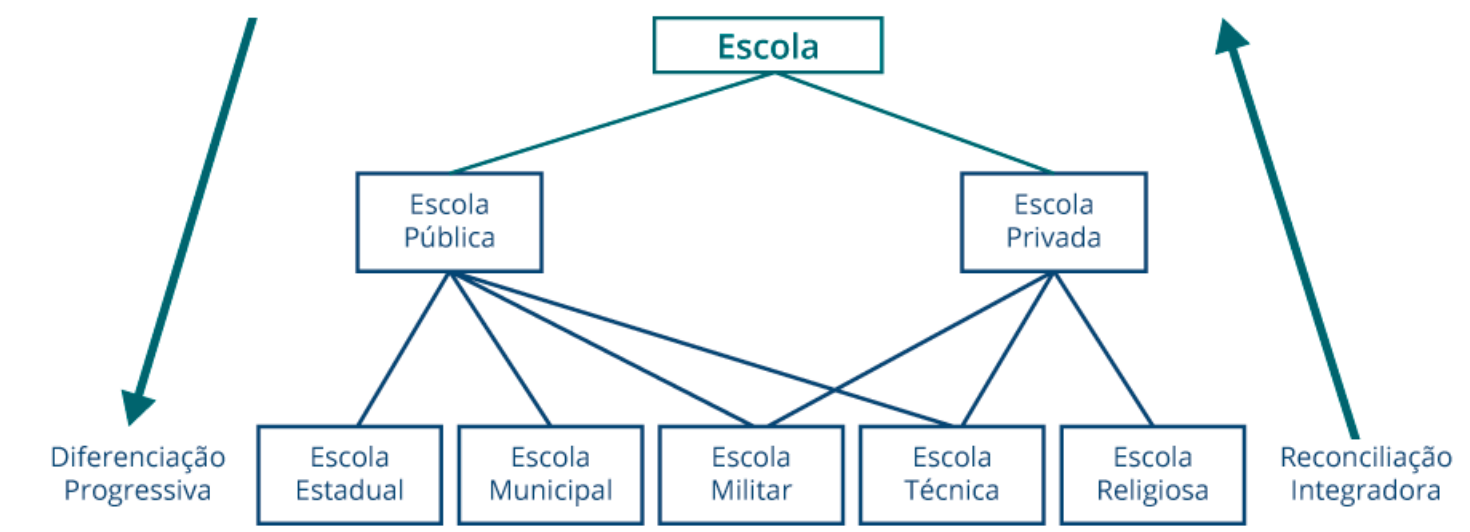

Fonte: Elaborado pelos autores, com base em Ausubel (2003).

Elucidados os conceitos básicos relativos à teoria de aprendizagem significativa de Ausubel (2003), no que concerne à aprendizagem de adultos, é possível fazer a ponte com a proposta de educar pela pesquisa. Demo (2009, 2011a, 2016a, 2016b, 2016c, 2018) não explica diretamente como a aprendizagem ocorre, apenas faz referência de que ela acontece de dentro para fora em um processo autopoiético que só aparece com expressão autoral. $\mathrm{O}$ autor concentra seus argumentos na defesa de que o estudante necessita ser autor em seu aprendizado e que o docente deve privilegiar metodologias que possibilitem aos estudantes ler, pesquisar, fazer sínteses e expressarem-se de forma autoral. Segundo Demo (2016c), "aprendizagem não se dá na aula, no repasse de conteúdo, mas na mente do estudante, desde que exercite atividades autorais, como ler, estudar, pesquisar, elaborar etc" (DEMO, 2016c, texto digital).

Ausubel (2003) argumenta que os indícios de aprendizagem significativa devem ser provenientes de instrumentos de coleta de dados 
substancialmente diferentes dos que foram utilizados para o pré-teste e do material didático utilizado pelo docente, ou seja, o estudante precisa reter a informação de forma não arbitrária e não literal em sua estrutura cognitiva para que seja possível representá-la de outras formas em que a simples memorização de informações não seja o suficiente. Isto nada mais é do que a expressão autoral discente defendida por Demo (2016c).

Seguindo esta proposta, o uso das mídias digitais, em particular do podcast, pode contribuir para que os possíveis indícios de aprendizagem significativa sejam elucidados, uma vez que podem ser utilizados pelos docentes como forma de expressão autoral dos discentes. A exemplo disso, tem-se a proposta de uso do podcast enquanto recurso de aprendizagem, que será apresentada na próxima seção.

\section{Metodologias ativas e formas de produzir, comunicar e representar o conhecimento}

Adotando com as ideias de Lames (2011), Ausubel (2003), e Demo (2011a), após compreender o que é aprender, o que é ensinar e como os alunos aprendem, o professor poderia exercitar sua expressão autoral por meio da elaboração de proposta metodológica própria, em que busca, por meio das mídias digitais, possibilitar aos estudantes uma experiência única de aprendizado. Embora a expressão autoral discente não necessite ser expressa por meio das mídias digitais, autores como Cruz (2009) e Prensky (2001) defendem a perspectiva de aproximação da linguagem dos estudantes pois assim, será possível estabelecer um vínculo entre o conteúdo a ser estudado e o que é do interesse dos alunos. Nesse quesito, a utilização dos diferentes tipos de mídias digitais como recurso de aprendizagem pode contribuir com o processo pedagógico.

Nosso entendimento é que o uso das mídias digitais como forma de expressão autoral discente completa a lacuna existente no elo entre a teoria de aprendizagem significativa, o educar pela pesquisa e as mídias digitais. 
Esse elo pode ser visualizado por meio do modelo reflexivo (Figura 3) proposto para a construção de metodologias com as mídias digitais, tendo como base a teoria de aprendizagem significativa à luz da perspectiva educativa do educar pela pesquisa.

Figura 3: Modelo reflexivo para a elaboração de propostas de uso das mídias digitais utilizando os pressupostos teóricos da aprendizagem significativa e do educar pela pesquisa.

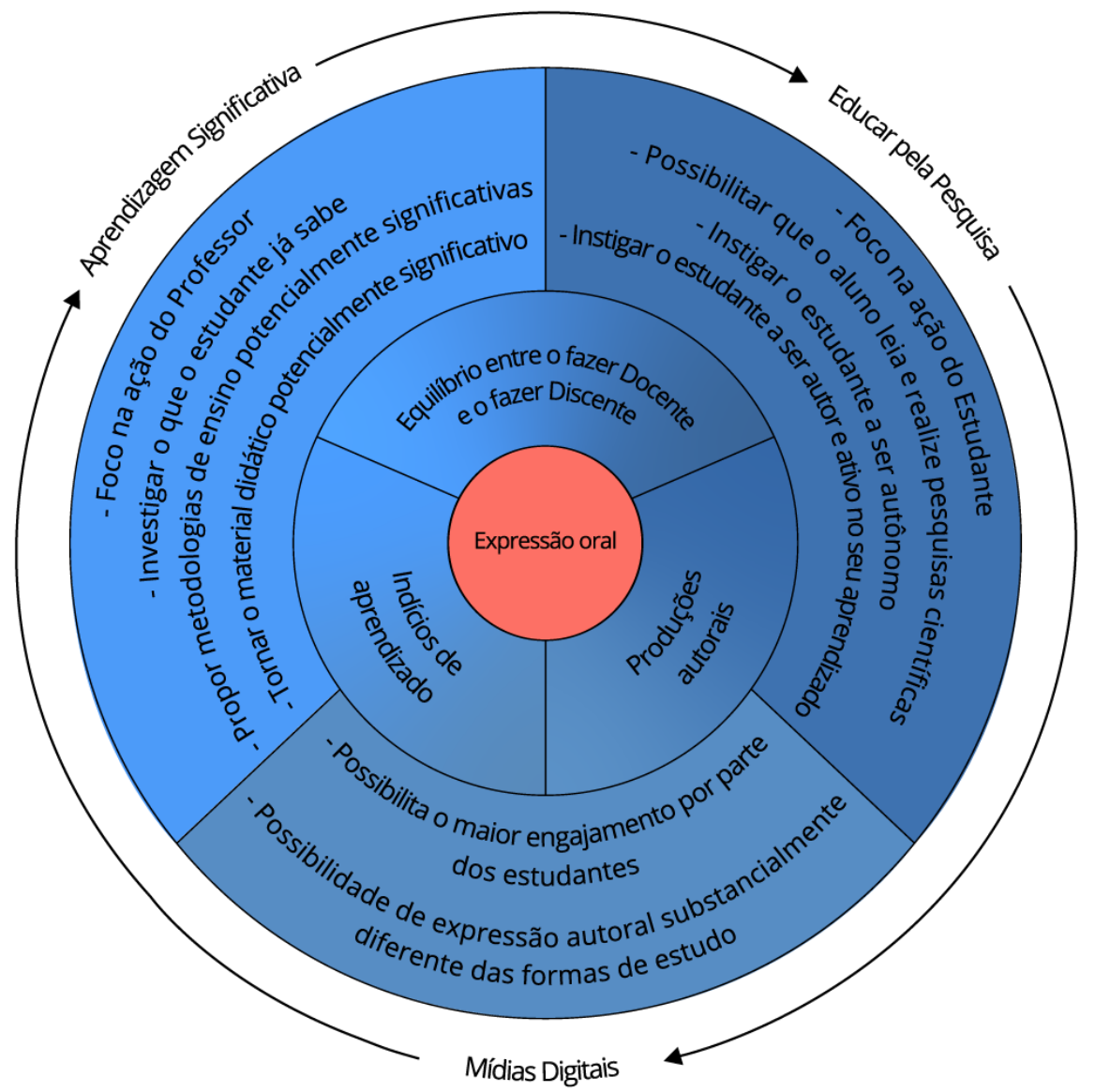

Fonte: Elaborado pelo segundo autor deste trabalho com base no referêncial teórico.

A parte mais externa do modelo descortina a interação entre os três eixos. A teoria de aprendizagem significativa, quando guiada pelos pressupostos teóricos do educar pela pesquisa, fornece um equilíbrio entre o fazer docente e o fazer discente. $\mathrm{O}$ educar pela pesquisa vale-se das mídias digitais como forma de aproximar os conteúdos trabalhados em períodos de 
estudos da linguagem dos estudantes, possibilitando um maior engajamento durante a realização das atividades de aprendizagem. $\mathrm{O}$ vínculo entre as mídias digitais e a aprendizagem significativa dá-se por meio dos indícios de aprendizagem que surgem da expressão autoral discente. Todos esses elementos compartilham de um ponto em comum, a expressão autoral tanto docente quanto discente.

Com base na reflexão proposta pelo modelo elaboramos uma prática pedagógica que utilizou a mídia podcast em contextos de aprendizagem. Conforme sugere um estudo realizado por Eugênio Freire (2013), a mídia podcast pode favorecer o desenvolvimento da autonomia de estudo nos aprendizes, além de possibilitar que eles sejam autores de seu aprendizado, o que é defendido por Demo (2011a). Freire (2013) também destaca que os produtores de podcasts elaboram seus programas, em grande medida mobilizados pelo anseio de serem ouvidos, o que, à luz da teoria de aprendizagem significativa de Ausubel (2003), pode ser encarado como predisposição para aprender, sendo essa uma das chaves para que esse tipo de aprendizagem, de fato, ocorra.

\section{Metodologia}

Como forma de caracterizar o estudo, utilizamos como referencial teórico as obras de Gil (2010), Knechtel (2014) e Moraes e Galiazzi (2013), que desvelam os caminhos que os projetos de pesquisa precisam trilhar. No entendimento do pesquisador, Knechtel (2014) fornece subsídios suficientes para que esta pesquisa seja caracterizada como sendo de cunho qualitativo. Além disso, o pesquisador optou por utilizar os procedimentos metodológicos que se aproximam aos de um estudo de caso, por entender que esse é o melhor caminho para alcançar os objetivos deste trabalho.

Posto isso, faz-se necessário caracterizar a unidade de pesquisa na qual este trabalho está centrado. O grupo pesquisado é composto por estudantes de graduação que estavam matriculados na disciplina Tópicos 
Especiais em Computação, no $2^{\circ}$ semestre de 2017. Essa disciplina integra a matriz curricular dos cursos de Sistemas de Informação, Engenharia da Computação, Engenharia de Software e Redes de Computadores da Universidade do Vale do Taquari - Univates. O grupo de estudantes foi formado por 20 homens e quatro mulheres, com faixa etária média de 26 anos. A pesquisa foi realizada durante nove encontros com duração de três horas cada.

A atividade foi realizada com os 24 estudantes que, durante as primeiras aulas, foram separados em grupos de quatro ou cinco integrantes. Ao final da pesquisa, elegemos por meio de alguns critérios, o Grupo 2 como sendo o grupo que teria seus dados analisados. Este grupo foi formado por 4 estudantes, todos homens, que serão chamados de Estudante 6, Estudante 7, Estudante 8 e Estudante 9, para manter a coerência com o estudo que deu origem a este trabalho. A temática por eles estudada foi o Node JS, que é uma plataforma utilizada para o desenvolvimento de aplicações.

Os dados foram coletados por meio de questionários, entrevistas, observação participante e análise documental. A caracterização de cada um destes instrumentos e como cada um deles se encaixa nesta proposta pode ser encontrada no trabalho que originou este artigo. Além disso, cabe destacar que a análise de dados foi realizada por meio do software NVIVO.

\section{Prática pedagógica}

Em seu trabalho, Freire (2013) apresenta diversos cenários nos quais a mídia pode ser inserida de modo a corroborar com os objetivos pedagógicos previamente delineados pelo professor. Além disso, Freire (2013) defende que o podcast pode ser utilizado nos diversos níveis de ensino, dentre os quais está o ensino superior.

Unindo os preceitos de Demo (2011a), Ausubel (2003) e Freire (2013) estruturamos a proposta didática prática que objetivou utilizar o podcast como instrumento de aprendizagem potencialmente significativa, em que os 
alunos foram estimulados a estudar de forma autônoma um tema por eles escolhido e, como resultado, criaram um episódio de podcast. A construção desse podcast deu-se mediante a elaboração de uma pesquisa científica, que foi utilizada para a elaboração da pauta que guiou a gravação dos episódios.

A prática realizada, desenvolvida ao longo de nove encontros de três horas cada, passou pelas seguintes etapas:

- Sensibilização dos estudantes: nesta etapa, o professor trabalhou com os estudantes o que é a mídia podcast e como eles podem usufruir desse tipo de mídia para complementar o aprendizado de sala de aula;

- Verbalização e desinibição: nesta etapa, o professor trabalhou com os estudantes a verbalização de suas opiniões e a desinibição frente aos colegas. Essa atividade foi realizada por meio de sessões de GV/GO4, que tiveram como base a audição de podcasts e textos de autoria do docente;

- Elaboração da pesquisa bibliográfica: a elaboração da pauta utilizada para a gra-vação do podcast foi construída com base em uma pesquisa bibliográfica realizada pelos estudantes;

- Produção dos podcasts: Após a elaboração da pauta, os alunos foram convidados a gravar seus podcasts. Para tanto, o professor disponibilizou o estúdio de rádio e o laboratório de captação de imagens para os estudantes que os quisessem utili-zar. Ao final, os alunos editaram seus podcasts, adicionando a eles trilha sonora, eliminando possíveis erros de gravação e privilegiando os conteúdos que conside-raram mais adequados;

- Avaliação da aprendizagem dos estudantes: de modo a buscar indícios de que a aprendizagem foi significativa, o professor solicitou que os estudantes elaboras-sem uma produção textual em

\footnotetext{
${ }^{4}$ GV/GO ou Grupo de Verbalização e Grupo de Observação é uma estratégia de ensino que, segundo Masetto (2003), permite desenvolver habilidades como: verbalizar, ouvir, observar e dialogar.
} 
forma de fragmentos. Essa atividade foi realizada de forma individual.

\section{Resultados}

O processo pelo qual os estudantes passaram durante a elaboração do podcast se aproxima da proposta de educar pela pesquisa, vislumbrada por Demo (2011a). Durante as atividades, os discentes foram constantemente instigados a lerem, pesquisarem e avaliarem informações. Eles precisaram realizar sínteses, exercitaram sua autonomia nos estudos e produziram de forma autoral o texto-base (pauta) e o episódio de podcast gravado. $\mathrm{O}$ potencial uso da mídia podcast enquanto recurso que possibilita estimular a autoria discente por meio da teoria do educar pela pesquisa de Demo (2011a) desnuda-se no momento em que os estudantes são instigados a falarem sobre a atividade realizada.

Estudante 9: Uma parte que não foi muito boa foi a quantidade de coisa que a gente teve que ler, por causa que, como ninguém dominava a tecnologia a gente teve que ler bastante. A gente leu pelo menos 1 livro e uns 3 artigos científicos cada um [...]

Estudante 7: Vi que preciso ler mais para que possa ter mais facilidade nesse tipo de tarefa, não somente para diálogos em aula, mas fora da aula também.

Nesses excertos, os estudantes demonstram sua percepção quanto ao fato de precisarem ler diversos materiais para terem subsídios a fim de elaborar a pauta e desenvolverem o diálogo durante o podcast. Demo (2011a) defende que aprender implica enfrentar desafios e que o mais importante é a profundidade da pesquisa e não a quantidade de conteúdos estudados.

Um aspecto que pode ter influenciado no engajamento demonstrado pelos estudantes foi a possibilidade de escolha da temática do podcast. Em 
seu discurso, o Estudante 6 acredita que a possibilidade de escolha da temática propiciou o bom nível de interação do grupo, o que, em sua visão, foi maior do que em trabalhos cujo tema é escolhido pelo docente.

Estudante 6: [...] a interação do grupo foi bem maior do que qualquer outro trabalho, não sei se é porque era uma tema que a gente escolheu e estava interessado realmente em fazer do que, "há, faz uma pesquisa sobre esse assunto da cadeira que a gente tá tendo" sabe. Não! foi um tema que a gente escolheu e pesquisou.

O Estudante 6 revela a postura ativa que adotou frente aos estudos e à forma com que lidou com a autonomia. A análise desse trecho, à luz de Demo (2011a; 2016a), traz à tona outra característica da educação com base em pesquisa: a relevância para o sujeito. Demo (2011a) defende que o docente deveria ter a habilidade de fazer a relação entre os conteúdos trabalhados e a vida dos estudantes, originando sentido e, por vezes, problematizando os conteúdos. Para o autor, “o desafio será aproximar o que o estudante prefere com aquilo que é profundo o suficiente para ser trabalhado no estudo" (DEMO, 2016a, texto digital). Nos dizeres do Estudante 6, é possível perceber a relevância da temática para o grupo quando ele afirma "estava interessado realmente em fazer" como argumento para "interação do grupo foi bem maior do que qualquer outro trabalho".

Cabe, neste momento, apresentar alguns indícios de aprendizagem demonstrados pelos estudantes. O primeiro indício, que pode ser destacado, está relacionado ao gerenciador de dependências da plataforma NodeJS.

\footnotetext{
Estudante 6: O NPM é o gerenciador de dependências do Node. Ele é responsável por executar, baixar todas as dependências do nosso projeto. Mas ele serve também como repositório para módulos e bibliotecas de terceiros e, tu falaste do package json, que é um arquivo de configuração justamente do nosso projeto, como o nome, quais são as dependências e alguns
} 
scripts que podemos usar pelo NPM são descritos nesse package json. A gente pode fazer, talvez, alguma similaridade com o Maven do Java e até mesmo o composer do PHP. Apesar de não serem totalmente iguais, eles possuem uma similaridade de função.

A forma com que o Estudante 6 relaciona as informações sobre os diferentes gerenciadores de dependências demonstra como a informação pode ter sido ancorada em seus subsunçores. Primeiro, ele apresenta uma ideia mais geral e inclusiva (gerenciador de dependências) e, depois, implicitamente demonstra reconhecer semelhanças e diferenças entre o NPM e outros gerenciadores de dependências. É possível que a informação relacionada ao NPM da plataforma NodeJS tenha sido ancorada na estrutura hierárquica do aprendiz por meio de diferenciação progressiva e reconciliação integradora. Nesse caso, Ausubel (2003) argumenta que é necessária a existência de subsunçores correlatos para que a ancoragem do novo conhecimento ocorra. A Figura 4 demonstra a possível estrutura cognitiva elucidada pelo estudante.

Figura 4: Possível estrutura hierárquica apresentada pelo Estudante 6

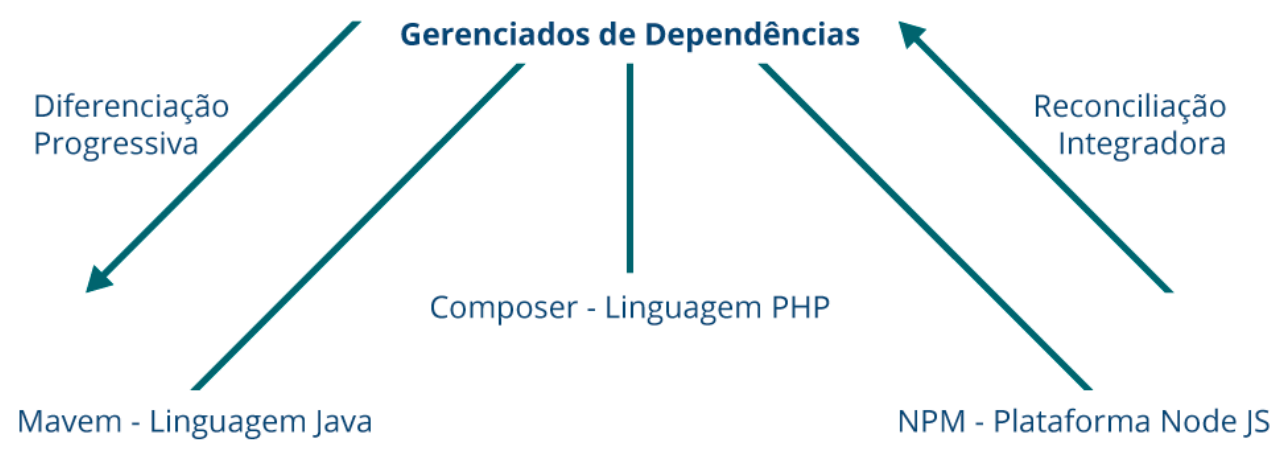

Fonte: Elaborado pelos autores, com base na análise dos dados.

De forma mais abrangente, a análise realizada com os resultados do pré-teste e pós-teste evidenciam que houve uma melhora significativa na quantidade de subsunçores apresentados pelos estudantes depois do período 
de estudos. Quanto a isso, o número de subsunçores presentes passou de oito, no pré-teste, para 38 no pós-teste.

\section{Considerações Finais}

A aproximação realizada neste estudo entre as mídias digitais, a teoria de aprendizagem significativa e o educar pela pesquisa, contribuíram para descortinar uma prática pedagógica potente. $\mathrm{O}$ amadurecimento da prática pedagógica desenvolvida ao longo deste trabalho só foi possível em virtude da imersão dos pesquisadores em um estudo relacionado aos processos de ensino e de aprendizagem, bem como de aquisição de autonomia por parte dos estudantes. A recorrente leitura de Ausubel (2003) e Demo (2004, 2009, 2011a, 2011b, 2016a, 2016b, 2016c, 2018) guiaram os pesquisadores por esses caminhos.

Como frutos deste trabalho, podem-se destacar a prática pedagógica proposta e o modelo reflexivo. A prática pedagógica proposta neste estudo qualifica-se como sendo uma possibilidade dentre as metodologias ativas disponíveis para que outros professores utilizem em suas atividades em sala de aula. Já o modelo reflexivo contribui para a elaboração de outras propostas de uso das mídias digitais utilizando os pressupostos teóricos da aprendizagem significativa e do educar pela pesquisa.

Ademais, quanto ao objetivo proposto por este trabalho que era investigar as implicações da utilização da mídia podcast enquanto estratégia para instigar a autonomia e autoria discente na aprendizagem dos estudantes da disciplina Tópicos Especiais em Computação, pode-se dizer que foi alcançado. Ausubel (2003) defende que os indícios de aprendizagem significativa são sutis e precisam ser cuidadosamente observados para que não sejam confundidos com mera memorização de informações. Mesmo assim, acreditamos que foi possível identificar indícios de que a aprendizagem para os estudantes envolvidos foi significativa. 


\section{Referências}

AUSUBEL, D. P. Aquisição e retenção de conhecimentos: uma perspectiva cognitiva. Lisboa: Plátano, 2003.

CARVALHO, A. A. C. et al. Integração de Podcast s no Ensino Universitário: Reacções dos Alunos. Revista Prisma.com: Revista de Ciências e Tecnologias de Informação e Comunicação de do CETEC.MEDIA, Porto, v. 1, n. 6, p.50-74, 2008. Disponível em: <http://revistas.ua.pt/index.php/prismacom/article/view/664>. Acesso em: 06 nov. 2016.

CRUZ, S. C. O podcast no ensino básico. In: CARVALHO, A. A. (Org.). Actas do Encontro sobre Podcasts. Braga: CIEd, p. 65-80, 2009. Disponível em: <http://repositorium.sdum.uminho.pt/bitstream/1822/9991/1/Cruz-2009Enc\%20sobre\%20Podcasts.pdf $>$. Acesso em: 30 set. 2016.

DEMO, P. APRENDIZAGEM AUTÊNTICA NA ERA DIGITAL: Envolvendo estudantes via pesquisa. 2016a. Disponível em: < https://bit.ly/2X9GR15 >. Acesso em: 07 mai. 2019.

\begin{tabular}{cccc} 
APRENDIZAGEM AUTOPOIÉTICA. 2009. & Disponível & em: \\
\hline <https://bit.ly/2EC3xQn $>$ Acesso em 07 mai 2019. & &
\end{tabular}

. ATIVIDADES DE APRENDIZAGEM: Sair da mania do ensino para comprometer-se com a aprendizagem do estudante. Campo Grande: Secretaria de Estado de Educação do Mato Grosso do Sul - SED/MS, 2018. Disponível em: <https://bit.ly/2wn6zDl >. Acesso em: 05 jan. 2019.

Educar pela pesquisa. 9. ed. Campinas: Autores Associados, 2011a.

. METODOLOGIAS ATIVAS: Estratégias para salvar a aula. 2016b. Disponível em: < https://bit.ly/2MedBVX >. Acesso em: 05 mai. 2019.

PAPEL DOCENTE. 2016c. Disponível em: <https://docs.google.com/document/u/1/d/1NLMbBeyJYq8RvxweAWtD3cMrU4zQN ueVoJ54Qi9kD10/pub>. Acesso em: 05 mai. 2019.

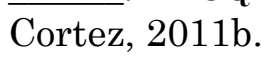

PESQUISA: PRINCÍPIO CIENTÍFICO E EDUCATIVO. 14. ED. São Paulo: Ser professor é cuidar que o aluno aprenda. Porto Alegre: Mediação, 2004.

DOMINGUES, N. S. O papel do vídeo nas aulas multimodais de matemática aplicada: uma análise do ponto de vista dos alunos. 2014. 125 p. Dissertação (mestrado) - Universidade Estadual Paulista, Instituto de Geociências e Ciências Exatas, 2014. Disponível em: <http://hdl.handle.net/11449/91019>. Acesso em: 03 jan. 2017.

FREIRE, E. P. A. Podcast na educação brasileira: natureza, potencialidades e implicações de uma tecnologia da comunicação. 2013. 338 f. Tese (Doutorado em 
Educação) - Universidade Federal do Rio Grande do Norte, Natal, 2013. Disponível em: <https://repositorio.ufrn.br/jspui/handle/123456789/14448>. Acesso em: 08 out. 2016.

GIL, A. C. Como elaborar projetos de pesquisa. 5. ed. São Paulo: Atlas, 2010.

KNECHTEL, M. do R. Metodologia da Pesquisa em Educação: Uma Abordagem Teórico-prática Dialogada [Livro eletrônico]. Curitiba: Intersaberes, 2014.

LAMES, L. da C. J. DOCÊNCIA NO ENSINO SUPERIOR: O USO DAS MÍDIAS DIGITAIS COMO ESTRATÉGIA PEDAGÓGICA. 2011. 159 f. Dissertação (Mestrado) - Curso de Mestrado em Ciências Contábeis, 1 Fundação Escola de Comércio Álvares Penteado - Fecap, São Paulo, 2011. Disponível em: $<$ http://tede.fecap.br:8080/jspui/bitstream/tede/494/1/Liliane_da_Costa_Jacobs_La mes.pdf>. Acesso em: 28 abr. 2019.

LEÃO, M. F.; REHFELDT, M. J. H; MARCHI, M. I. PRODUÇÃO DE VÍDEOS COM ATIVIDADES EXPERIMENTAIS PAR A DINAMIZAR O ESTUDO DOS CICLOS BIOGEOQUÍMICOS E FAVO RECER A CONSTRUÇÃO DE APRENDIZAGENS COM SIGNIFICADO. Revista Tecnologias na Educação, [s. L.], v. 12, p.1-11, jul. 2015. Disponível em: <http://tecedu.pro.br/wpcontent/uploads/2015/07/Art12-vol12-julho2015.pdf>. Acesso em: 03 jan. 2017.

LÉVY, P; COSTA, C. I. As tecnologias da inteligência: o futuro do pensamento na era da informática. Rio de Janeiro: 34, 1997.

MASETTO, M. T. Competência pedagógica do professor universitário. São Paulo: Summus, 2003.

MORAES, R; GALIAZZI, M. do C. Análise textual discursiva. 2. ed. Ijuí: Unijuí, 2013.

MOREIRA, M. A. O QUE É AFINAL APRENDIZAGEM SIGNIFICATIVA? Qurriculum, La Laguna, Espanha, v. 0, n. 0, p.29-56, mar. 2012. Disponível em: < http://moreira.if.ufrgs.br/oqueeafinal.pdf >. Acesso em: 10 jan. 2017.

MATURANA, H./VARELA, F. De Máquinas y Seres Vivos - Autopoiesis: la organización de lo vivo. Editorial Universitaria, Santiago: 1994.

MOURA, A. M. C; CARVALHO, A. A. A. Podcast: uma ferramenta para usar dentro e fora da sala de aula. 2006. In Rui José \& C. Baquero, (eds), Conference on Mobile and Ubiquitous Systems - CSMU 2006. Universidade do Minho: Braga, p. 155-158, 2006. Disponível em:< http://repositorio.uportu.pt:8080/handle/11328/476>. Acesso em: 06 nov. 2016.

PRENSKY, M. Digital Natives, Digital Immigrants: part 1. On The Horizon, S. L., v. $9, \quad$ n. $5, \quad$ p.1-6, 2001. Disponível em: $<$ http://www.marcprensky.com/writing/Prensky - Digital Natives, Digital Immigrants - Part1.pdf>. Acesso em: 23 jan. 2017. 
REHFELDT, M. J. H. A aplicação de modelos matemáticos em situações-problema empresariais com o uso do software LINDO. 2009, 299 f. Tese (Doutorado) Programa de Pós-Graduação em Informática na Educação da Universidade Federal do Rio Grande do Sul, Porto Alegre, 2009.

SAEED, N. Integration and acceptance of Web 2.0 technologies in higher education. 2010. 200 f. Tese (Doctor of Philosophy) - Melbourne, Swinburne University of Technology 2010.

Disponível

em: $<$ http://researchbank.swinburne.edu.au/vital/access/manager/Repository/swin:1853 5>. Acesso em: 17 out. 2016.

Recebido em maio de 2019. Aprovado em outubro de 2019. 